\title{
Discussion: Hydraulic jump in arbitrary prismatic channel
}

Jian-min Zhang PhD

Professor, State Key Laboratory of Hydraulics and Mountain River Engineering, Sichuan University, Chengdu, China

\section{Wei-lin Xu PhD}

Professor, State Key Laboratory of Hydraulics and Mountain River Engineering, Sichuan University, Chengdu, China

\section{Peng-zhi Lin PhD}

Professor, State Key Laboratory of Hydraulics and Mountain River Engineering, Sichuan University, Chengdu, China

\section{Yu-rong Wang PhD}

Associate Professor, State Key Laboratory of Hydraulics and Mountain River Engineering, Sichuan University, Chengdu, China

\section{Yong Peng MSC}

PhD Candidate, School of Engineering, University of Liverpool, Liverpool, UK Ali R. Vatankhah PhD

Assistant Professor, Irrigation and Reclamation Engineering Department, University College of Agriculture and Natural Resources, University of Tehran, Karaj, Iran

Leili Azarbu BSc

MSc Student, Irrigation and Reclamation Engineering Department, University College of Agriculture and Natural Resources, University of Tehran, Karaj, Iran Mohammad Hosein Omid PhD

Professor, Irrigation and Reclamation Engineering Department, University College of Agriculture and Natural Resources, University of Tehran, Karaj, Iran

\section{Contribution by A. R. Vatankhah, L. Azarbu and M. H. Omid}

\subsection{Introduction}

The contributors would like to thank the authors for proposing an approximation of the sequent depth ratio of the hydraulic jump formed in an arbitrary gradually expanding channel (Zhang et al., 2012) and would like to draw attention to a few points.

A prismatic channel has an unvarying cross-section with position along the channel (Jeppson, 2011). A gradually expanding channel is not a prismatic one from a hydraulic standpoint and thus using the term 'expanding prismatic channel' in the paper by Zhang et al. (2012) is inappropriate.

\subsection{Assumption of a quarter-elliptical longitudinal water surface profile}

The authors assumed that the projected area of the water surface onto the $y-z$ plane is elliptic, as shown in Figure 8. In this case, for a large expansion angle $\left(b_{2}-b_{1} \geqslant 2 m h_{1}\right)$, the side-wall pressure force in the $x$-direction, $\boldsymbol{F}_{\mathrm{s} x}$, can be calculated from

$$
\begin{aligned}
\frac{\boldsymbol{F}_{\mathrm{s} x}}{\rho \boldsymbol{g}}= & \int_{0}^{m h_{1}}(y / m)^{2} \mathrm{~d} y+\int_{m h_{1}}^{\left(b_{2}-b_{1}\right) / 2}\left(h_{1}+\left(h_{2}-h_{1}\right)\right. \\
& \left.\times\left[1-\left(\frac{y-\left(b_{2}-b_{1}\right) / 2-m h_{2}}{\left(b_{2}-b_{1}\right) / 2+m\left(h_{2}-h_{1}\right)}\right)^{2}\right]^{1 / 2}\right)^{2} \mathrm{~d} y \\
& +\int_{\left(b_{2}-b_{1}\right) / 2}^{m h_{2}+\left(b_{2}-b_{1}\right) / 2}\left(h_{1}+\left(h_{2}-h_{1}\right)\right. \\
& \times\left[1-\left(\frac{y-\left(b_{2}-b_{1}\right) / 2-m h_{2}}{\left(b_{2}-b_{1}\right) / 2+m\left(h_{2}-h_{1}\right)}\right)^{2}\right]^{1 / 2} \\
& \left.-\frac{\left[y-\left(b_{2}-b_{1}\right) / 2\right]}{m}\right)^{2} \mathrm{~d} y
\end{aligned}
$$

It is worth noting that in a prismatic trapezoidal channel $\left(b_{2}=b_{1}\right), \boldsymbol{F}_{\mathrm{s} x}$ should be zero. But, according to Figure 9, for a prismatic trapezoidal channel $\left(b_{2}-b_{1}=0\right.$ and $\left.m \neq 0\right), A_{2}$ and $\boldsymbol{F}_{\mathrm{s} x}$ are not zero. In this case, Equation 14 takes the form

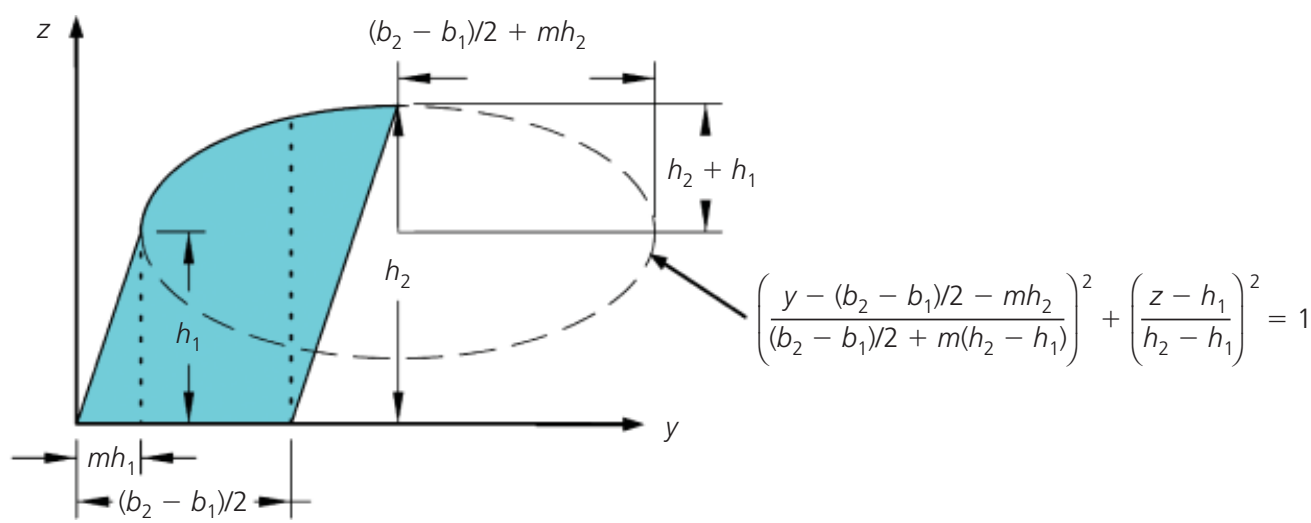

Figure 8. Projected area onto $y-z$ plane for an expanding trapezoidal channel assuming a quarter-elliptical longitudinal water surface profile 


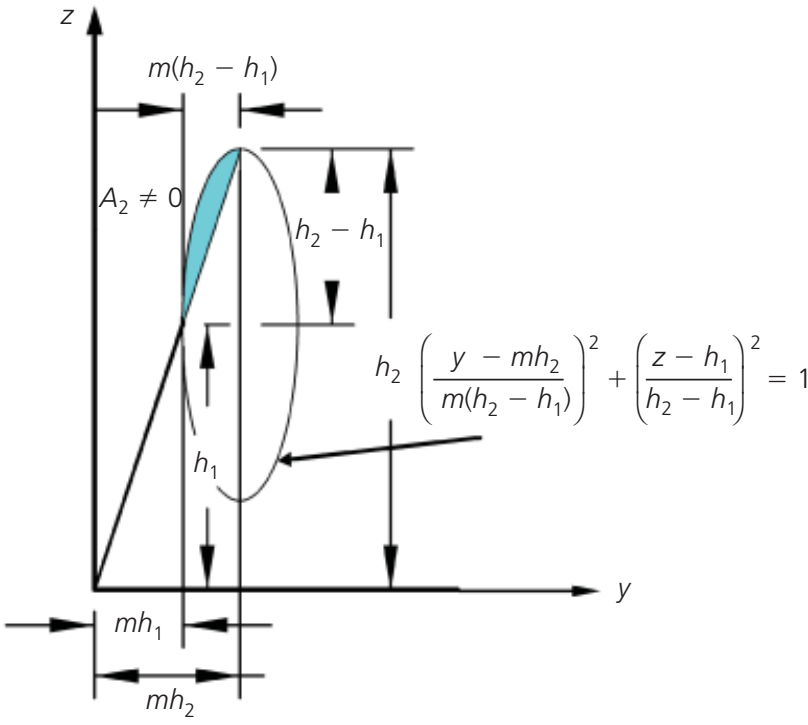

Figure 9. Projected area onto $y-z$ plane for a prismatic trapezoidal channel assuming a quarter-elliptical longitudinal water surface profile as suggested by Zhang et al. (2012)

$$
\begin{aligned}
\frac{\boldsymbol{F}_{\mathrm{s} x}}{\rho \boldsymbol{g}}= & \int_{m h_{1}}^{m h_{2}}\left(h_{1}+\left(h_{2}-h_{1}\right)\left[1-\left(\frac{y-m h_{2}}{m\left(h_{2}-h_{1}\right)}\right)^{2}\right]^{1 / 2}\right. \\
& -y / m)^{2} \mathrm{~d} y \\
\text { 15. } \quad= & \frac{10-3 \pi}{6} m\left(h_{2}-h_{1}\right)^{3}
\end{aligned}
$$

This result is different from that obtained by substituting $b_{2}=b_{1}$ into Equation 5 of Zhang et al. (2012); that is

$$
\frac{1}{6} \times m\left(h_{2}-h_{1}\right)^{2}\left[4\left(h_{2}-h_{1}\right)+3 h_{1} \pi\right]
$$

As noted, $\boldsymbol{F}_{\mathrm{s} x} \neq 0$, but, in a prismatic trapezoidal channel, the side-wall pressure force should be zero. Figure 9 indicates that the projected area onto the $y-z$ plane for a prismatic trapezoidal channel is not acceptable from a hydraulic viewpoint. This may be attributed to an incorrect projecting procedure or an unrealistic assumption of the quarter-elliptical longitudinal water surface profile. This inconsistency may be removed by assuming a linear longitudinal water surface profile as shown in Figure 10.

\subsection{Using a linear longitudinal water surface profile} For computation of the side-wall pressure force in the $x$-direction, two cases should be considered - a large expansion angle $\left(b_{2}-\right.$ $\left.b_{1} \geqslant 2 m h_{1}\right)$ and a small expansion angle $\left(b_{2}-b_{1}<2 m h_{1}\right)$.

For a large expansion angle in a trapezoidal expanding channel
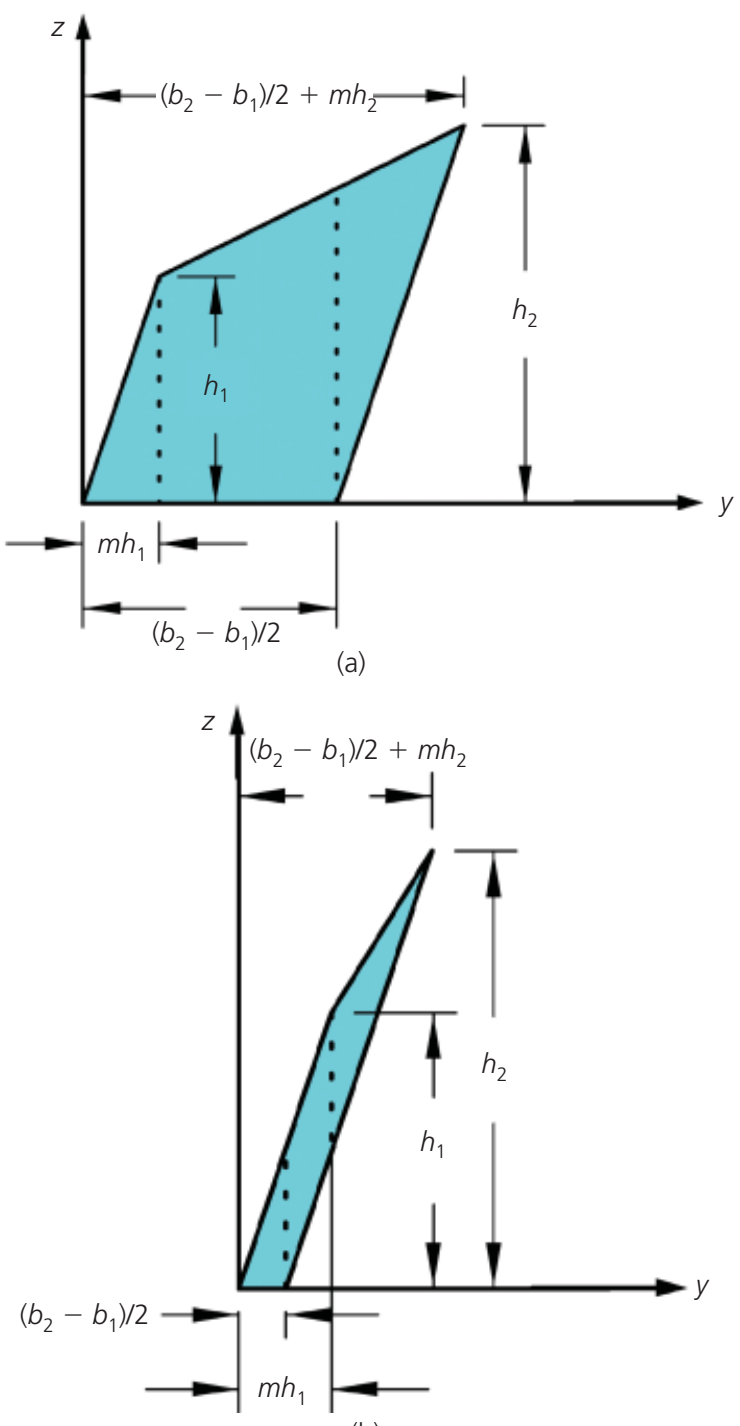

(b)

Figure 10. Projected area onto $y-z$ plane for an expanding trapezoidal channel assuming a linear longitudinal water surface profile: (a) large expansion angle; (b) small expansion angle

$$
\begin{aligned}
\frac{\boldsymbol{F}_{\mathrm{s} x}}{\rho \boldsymbol{g}}= & \int_{0}^{m h_{1}}(y / m)^{2} \mathrm{~d} y+\int_{m h_{1}}^{\left(b_{2}-b_{1}\right) / 2} \\
& \times\left(h_{1}+\frac{h_{2}-h_{1}}{\left(b_{2}-b_{1}\right) / 2+m\left(h_{2}-h_{1}\right)}\left(y-m h_{1}\right)\right)^{2} \mathrm{~d} y \\
& +\int_{\left(b_{2}-b_{1}\right) / 2}^{m h_{2}+\left(b_{2}-b_{1}\right) / 2} \\
& \times\left(h_{1}+\frac{h_{2}-h_{1}}{\left(b_{2}-b_{1}\right) / 2+m\left(h_{2}-h_{1}\right)}\left(y-m h_{1}\right)\right. \\
& \left.-\frac{\left[y-\left(b_{2}-b_{1}\right) / 2\right]}{m}\right)^{2} \mathrm{~d} y \\
= & \frac{\left(b_{2}-b_{1}\right)}{6} \frac{\left[\left(b_{2}-b_{1}\right)\left(h_{1}^{2}+h_{1} h_{2}+h_{2}^{2}\right)-2 m h_{1}^{3}\right]}{\left(b_{2}-b_{1}\right)+2 m\left(h_{2}-h_{1}\right)}
\end{aligned}
$$


In a rectangular expanding channel $m=0$, and thus the governing equation takes the form

$$
\begin{aligned}
\frac{\boldsymbol{F}_{\mathrm{s} x}}{\rho \boldsymbol{g}} & =\int_{0}^{\left(b_{2}-b_{1}\right) / 2}\left(h_{1}+\frac{h_{2}-h_{1}}{\left(b_{2}-b_{1}\right) / 2} y\right)^{2} \mathrm{~d} y \\
17 . \quad & =\frac{\left(b_{2}-b_{1}\right)\left(h_{1}^{2}+h_{1} h_{2}+h_{2}^{2}\right)}{6}
\end{aligned}
$$

Similarly, for a small expansion angle in a non-prismatic trapezoidal channel $(m \neq 0)$

$$
\begin{aligned}
\frac{\boldsymbol{F}_{\mathrm{s} x}}{\rho \boldsymbol{g}}= & \int_{0}^{\left(b_{2}-b_{1}\right) / 2}(y / m)^{2} \mathrm{~d} y+\int_{\left(b_{2}-b_{1}\right) / 2}^{m h_{1}} \\
& \times\left(\frac{y}{m}-\frac{\left[y-\left(b_{2}-b_{1}\right) / 2\right]}{m}\right)^{2} \mathrm{~d} y+\int_{m h_{1}}^{m h_{2}+\left(b_{2}-b_{1}\right) / 2} \\
& \times\left(h_{1}+\frac{h_{2}-h_{1}}{\left(b_{2}-b_{1}\right) / 2+m\left(h_{2}-h_{1}\right)}\left(y-m h_{1}\right)\right. \\
& \left.-\frac{\left[y-\left(b_{2}-b_{1}\right) / 2\right]}{m}\right)^{2} \mathrm{~d} y \\
= & \frac{\left(b_{2}-b_{1}\right)^{2}}{12} \frac{\left[m h_{2}+2 m h_{1}-\left(b_{2}-b_{1}\right) / 2\right]}{m^{2}}
\end{aligned}
$$

\subsection{Conclusion}

This discussion has dealt with the side-wall pressure force in the $x$-direction for a hydraulic jump in a horizontal, gradually expanding trapezoidal channel. A distinction is made between assuming a quarter-elliptical longitudinal water surface profile and a linear one. From a hydraulic standpoint, using the elliptic water surface profile yields a non-zero side-wall pressure force in the $x$-direction for prismatic channels. Thus, a linear longitudinal water surface profile is proposed, which seems more realistic. Moreover, it has been shown that the side-wall pressure force formulation is different for small and large expansion angles. The proposed linear equation for the water surface profile needs to be verified using experimental data.

\section{Acknowledgement}

The authors gratefully acknowledge support provided by the Center of Excellence for Evaluation and Rehabilitation of Irrigation and Drainage Networks, University of Tehran.

\section{Authors' reply}

First, we would like to thank the contributors for their attention and contribution to the original paper (Zhang et al., 2012).

The assumption of an elliptic curve for the water surface profile and its projection in the $x$-direction is used in the original paper and is based on experiments by Hager (1985) and Omid et al. (2007). The contributors proposed a linear longitudinal water surface profile for computing the side-wall pressure force in the $x$-direction. It is the opinion of the authors that the linear distribution is also a kind of simple approximation for determining the distribution of the side-wall pressure force.

Furthermore, computing the side-wall pressure force with the water surface profile and then projecting onto the $x$-direction is also an approximate method. In a hydraulic jump, due to the effect of entrainment, the side-wall pressure force and the water surface profile distribution are not consistent. The side-wall pressure force is neither elliptical nor linear in distribution. However, we agree with the linear approximation proposed here.

The purpose of this discussion is to unify the hydraulic jump formula for an expanding trapezoidal channel and a prismatic trapezoidal channel. In order to achieve this, one problem that needs to be addressed is that, for projection of the side-wall pressure force in the $x$-direction, the projected area is

$$
A_{\mathrm{s} x}=A_{\mathrm{s}} \times \sin \left(\frac{b_{2}-b_{1}}{2 L_{\mathrm{j}}}\right)
$$

when $b_{2}-b_{1}=0, A_{\mathrm{s}}=0$.

In Equation 14, when $b_{2}-b_{1}=0, \boldsymbol{F}_{\mathrm{s} x} \neq 0$; the main reason for this is the use of the water surface profile of the hydraulic jump to represent the side-wall pressure force. Because of the good agreement between the experimental results and prediction by the proposed formula, which is based on the assumption of an elliptic curve for the water surface profile in the original paper, the applicability of the formula for a prismatic trapezoidal channel is ignored in the original paper. In this discussion, the contributors propose a linear distribution for the projection of the side-wall pressure force to the $x$-direction. Furthermore, they proposed a unified formula that can be used for a hydraulic jump in both an expanding trapezoidal channel and a prismatic trapezoidal channel. This is an improvement on work presented in the original paper. We therefore agree with the points raised regarding the side-wall pressure force and appreciate this contribution.

In fact, no part of the distribution of the side-wall pressure force along the flow direction and its projection in the $x$-direction is linear or elliptic. We suggest that it is more realistic to compute the component of the side-wall pressure force in the $x$-direction, $\boldsymbol{F}_{\mathrm{s} x}$, based on the actual side-wall pressure force and including the effect of aeration. However, so far, using a linear distribution still is the most simple and effective.

Once again, we thank the discussers for their attention to the original paper and for this contribution. 


\section{REFERENCES}

Hager WH (1985) Hydraulic jump in non-prismatic rectangular channels. Journal of Hydraulic Research 23(1): 21-23.

Jeppson RW (2011) Open Channel Flow: Numerical Methods and Computer Applications. CRC Press, Boca Raton, FL, USA.

Omid MH, Esmaeeli M and Narayanan R (2007) Gradually expanding hydraulic jump in a trapezoidal channel. Journal of Hydraulic Research 45(4): 512-518.

Zhang J, Xu W, Lin P and Wang Y (2012) Briefing: Hydraulic jump in arbitrary prismatic channel. Proceedings of the Institution of Civil Engineers - Water Management 165(3): 141-145. See http://dx.doi.org/10.1680/wama.2012. 165.3.141 (accessed 20/12/2012).

\section{WHAT DO YOU THINK?}

To discuss this paper, please email up to 500 words to the editor at journals@ice.org.uk. Your contribution will be forwarded to the author(s) for a reply and, if considered appropriate by the editorial panel, will be published as a discussion in a future issue of the journal.

Proceedings journals rely entirely on contributions sent in by civil engineering professionals, academics and students. Papers should be 2000-5000 words long (briefing papers should be 1000-2000 words long), with adequate illustrations and references. You can submit your paper online via www.icevirtuallibrary.com/content/journals, where you will also find detailed author guidelines. 